in vivo 31 : $999-1002(2017)$

doi:10.21873/invivo.11160

\title{
Ileocecal Obstruction Due to Endometriosis - A Case Report and Literature Review
}

\author{
NICOLAE BACALBASA ${ }^{1}$, IRINA BALESCU ${ }^{2}$ and ALEXANDRU FILIPESCU ${ }^{1,3}$ \\ 1 "Carol Davila" University of Medicine and Pharmacy, Bucharest, Romania; \\ 2 "Ponderas Academic Hospital”, Bucharest, Romania; \\ 3 “Elias” Emergency University Hospital, Bucharest, Romania
}

\begin{abstract}
Endometriosis is a common finding in premenopausal women and a significant number of cases presenting digestive tract involvement at the time of diagnosis. However, most of these patients present pelvic nodules involving the rectosigmoidian junction, other digestive tract segments being less commonly affected. We present the case of a 37-year-old nulliparous woman who presented for diffuse abdominal pain and vomiting; she was diagnosed with complete ileocecal obstruction due to an endometriosis nodule in association with bilateral ovarian endometriosis lesions invading the rectosigmodian wall. A right colectomy with ileocolic anastomosis in association with bilateral cystectomy and rectosigmodian resection was successfully performed. The histopathological examination confirmed the endometriosic origin of the nodules invading the rectosigmodian and ileocecal wall, that was similar to the one described at the level of the ovarian cysts.
\end{abstract}

Endometriosis represents a benign condition which has been described in up to $15 \%$ of premenopausal women (1). This pathological finding has a peak incidence in the third and fourth decade of age, and is characterized by the presence of extrauterine endometrial tissue $(2,3)$. The most widely recognized theory is the one of retrograde menstruation, leading to the serosal intraperitoneal implantation of the cellular islets $(3,4)$. These lesions will induce local inflammation and fibrosis, inducing the development of adherences with the surrounding pelvic viscera.

Gastrointestinal involvement is present in up to $37 \%$ of cases, up to $95 \%$ of them presenting colorectal lesions $(1,5)$.

This article is freely accessible online.

Correspondence to: Irina Balescu, "Ponderas Academic Hospital", Bucharest, Romania. Tel: +40 724077709, e-mail: irina.balescu@ ponderas-ah.ro

Key Words: Endometriosis, ileocecal valve, obstruction.
Other lesions such as small bowel nodules have been rarely seen. In the study conducted by MacAfee et al. and published in 1960 involving 7,177 cases, although digestive tract involvement was reported in 803 cases, only 29 of them presented lesions involving the small bowel. Moreover, only nine of the 29 cases presented clinical signs of small bowel obstruction (6). The most commonly involved mechanisms leading to the apparition of bowel obstruction at this level consist of fibrosis and thickening of the muscular layer (5, 7). In rare cases, complete transmural involvement of the digestive wall has been reported, inducing the apparition of intestinal bleeding, bowel intussusception, perforation, perforation or even malignant transformation $(8,9)$.

\section{Case Report}

A 37-year-old nulliparous woman presented for diffuse abdominal pain and vomiting, symptoms that had been developed during the last three days. The patient reported a medical history of infertility and ovarian cyst endometriosis, a laparoscopic cystectomy being performed two years before. At the time of the actual presentation, the clinical examination revealed the presence of a diffuse abdominal distension, while the abdominal ultrasound described the presence of diffuse small bowel distension in association with a small amount of free peritoneal fluid and bilateral ovarian cysts. The transvaginal ultrasound confirmed the presence of bilateral ovarian cysts with endometriosic aspect (Figure 1). The patient was submitted to a computed tomography which revealed the presence of a complete obstruction at the level of the ileocecal valve so the patient was submitted to surgery. Intraoperatively a large nodule creating an extrinsic compression of the ileocecal valve was found, in association with bilateral ovarian lesions invading the rectosigmodian junction (Figures 2 and 3). A right ileocolectomy with ileo-colic anastomosis and bilateral cystectomy was performed; in the meantime the affected area of the rectosigmoidian loop was resected, while the continuity of the digestive tract was reestablished through an 
end to end anastomosis. The postoperative course was uneventful, the patient being discharged in the fifth postoperative day. The histopathological examination confirmed the endometriosic origin for the ovarian lesions for the ileocecal nodule and for the rectosigmodian one.

\section{Discussion}

The first case of digestive tract involvement in patients with endometriosis was reported by Sampson in 1924, who described the presence of sigmoidian involvement as part of extended endometriosic lesions, the incriminated mechanism being retrograde menstruation (10). Other theories regarding endometriosis formation involve the metaplastic transformation of pluripotent peritoneal mesothelium, of the mullerian remnants, the dissemination of endometriosis cells along the neural sheaths, or the apparition of genetic alterations (4, 11-13).

Endometriosic lesions located on the small bowel serosa are commonly seen, the most common form of presentation being the one of small disseminated deposits (measuring less than $2 \mathrm{~cm}$ ). The macroscopic aspect is the one of patchy grey glistening lesions and they are usually asymptomatic. In all these cases, these lesions are incidentally found during surgery for other pathologies.

Although intestinal involvement is a common finding in women with endometriosis, intestinal obstruction caused by this pathological finding is rare; this fact is mainly explained by the location of the invaded digestive structures. The most commonly affected segment is the rectosigmoidian colon; most often lesions developed at this level will lead to the apparition of constipation, rectal bleeding or modified aspect of the stool. Other digestive tract organs affected by endometriosis are represented by the small bowel (in 2-16\% of cases), appendix (3-18\% of cases) and caecum (in $2-5 \%$ of cases) (14).

Once the islets of endometriosis appear on the bowel serosa, a process of neovascularization will develop, the main incriminated promoting agent being the vascular endothelial growth factor (VEGF) (15). In these conditions, the foci of small bowel endometriosis will develop a continuous growth process, leading to invasion of the mucosa in up to $10 \%$ of cases (16).

Complete bowel obstruction is rarely seen in patients with endometriosis; however, it seems that this situation is more commonly found in women presenting with rectosigmoidian involvement. Small bowel obstruction due to endometrial lesions is a very uncommon situation, representing only $0.7 \%$ of all surgical procedures for endometriosis (17). Synchronous rectosigmoidian and ileal obstruction is not a common situation, the pattern of apparition of this condition being intensively studied. Moreover, attention was focused on determining whether there is an equal distribution of the lesions on the two pelvic sides (18). It seems that the most commonly affected structures on the left side are represented by the adnexa, ureter, rectosigmoidian loop and uterosacral ligament, while on the right side the most commonly involved structures include the inguinal canal and the sciatic nerve (18). The theory of retrograde menstruation corroborated with close proximity between the rectosigmodian loop and the left tube might explain why rectosigmodian involvement is more commonly seen when compared to ilececal involvement (19).

One of the largest studies regarding the topography of pelvic viscera involvement in cases with endometriosis was the one conducted by Vercellini et al. and published in 2004. Vercellini's review included 68 studies and 337 patients with intestinal endometriosis. Among these cases, the authors reported 84 right sided resections, 245 left sided resections and eight bilateral resections (18).

When it comes to the most efficient treatment, multiple therapeutic options such as oral contraceptives, intrauterine administration of levonorgestrel, or danazol has been proposed. However, these therapies can be proposed only in cases presenting non-complicated lesions (20). All the other cases presenting after the apparition of certain complications or who do not report a favorable response to these therapies, should be submitted to surgery. Whenever surgery is performed, a close inspection of the whole peritoneal cavity should be performed in order to identify and remove all the lesions. As for the patients presenting rectosigmoidian involvement, a close inspection of the distal ileum and cecum are strongly recommended, synchronous lesions of the two segments being frequently reported. The utility of this exhaustive exploration might be best demonstrated by one of the cases reported by Carrasco et al.; the patient, a 34-year-old patient who had been previously submitted to surgery for rectosigmodian endometriosis, at that moment a rectosigmoidian resection and diverting ileostomy being performed developed acute small bowel occlusion three months after closure of the prophylactic ostomy. The patient was resubmitted to surgery, an ileal infiltrating nodule of endometriosis being found; due to this reason a second digestive resection (of the affected ileal loop) was also performed with good results (21).

Due to the rarity of cases, experience regarding management of small bowel and rectosigmodian obstruction due to endometriosis is rather limited to few case reports, only few case series being reported so far. One of the most important studies about this subject was conducted by Carrasco et al. and published in the Taiwanese Journal of Obstetrics and Gynecology in 2017. The study included 150 patients with deep endometriosis, submitted to surgery between 2006 and 2014 in LaPaz University Hospital, Madrid, Spain. Among these cases only seven patients presented bowel involvement, the main symptoms including catamenial pseudo-obstruction, chronic pelvic pain, and 

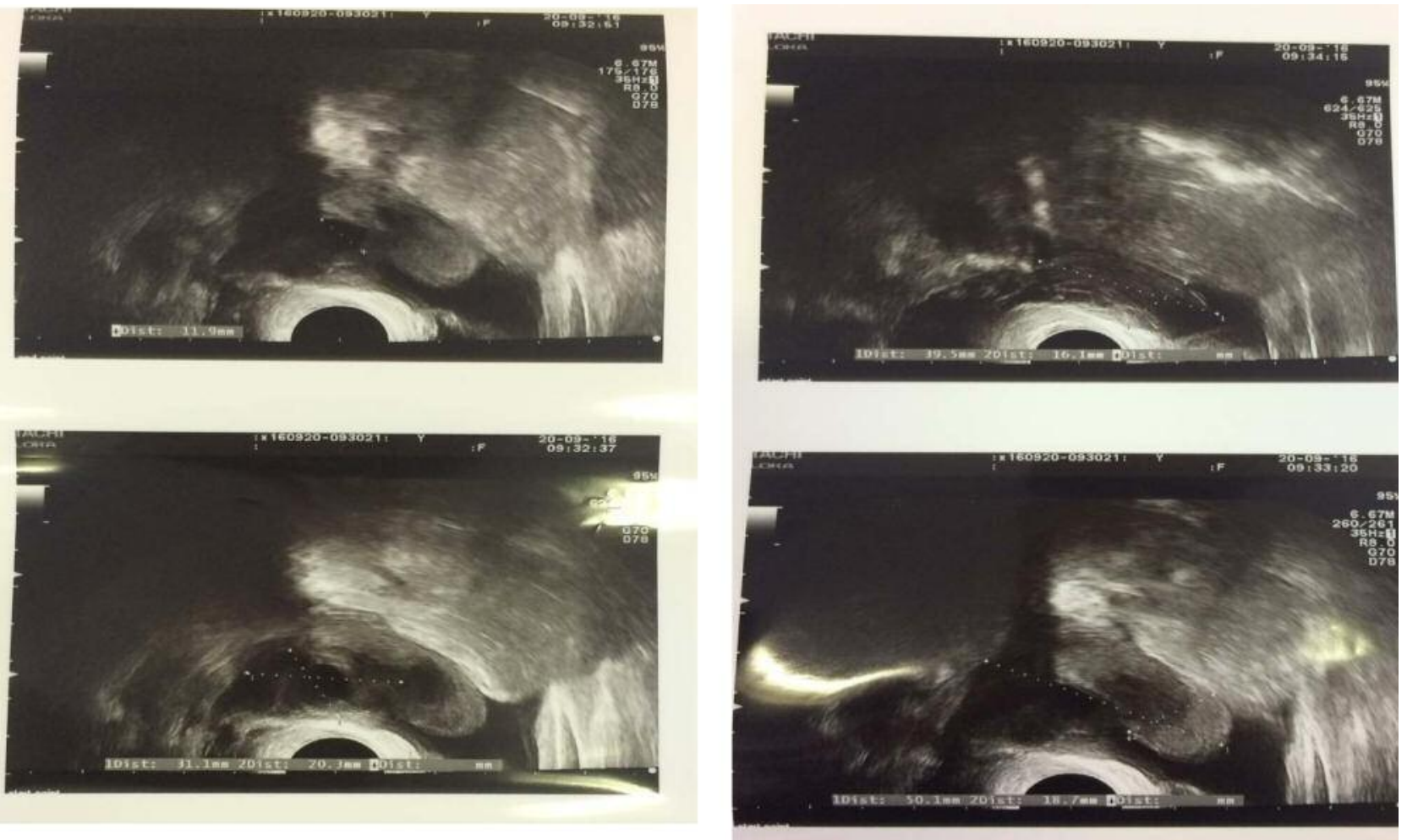

Figure 1. Transvaginal ultrasonography revealed the presence of bilateral ovarian endometriomas.

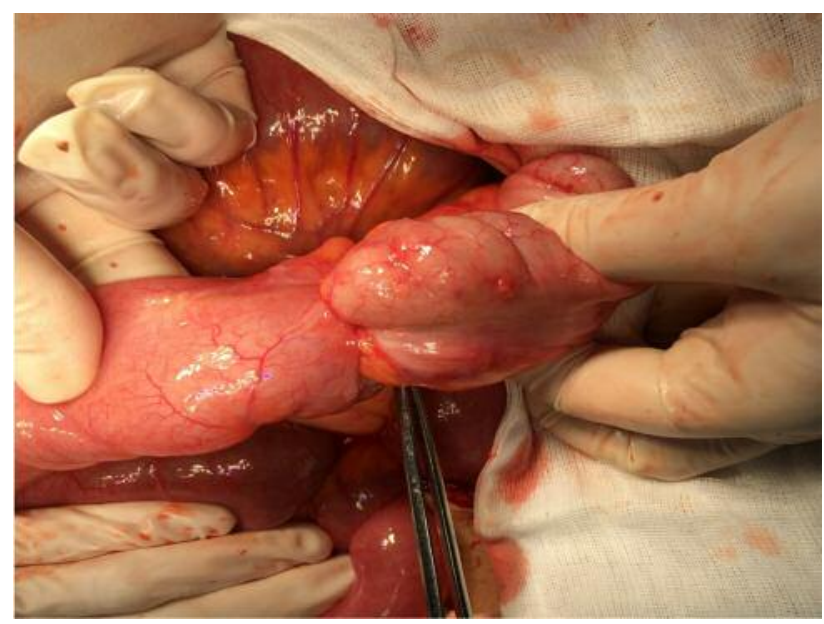

Figure 2. Complete obstruction of the ileocecal valve.

bowel obstruction. All patients were initially submitted to medical treatment consisting of oral contraceptives, levonorgestrel intrauterine devices or gonadotropin releasing hormone. However, all cases were submitted to surgery,

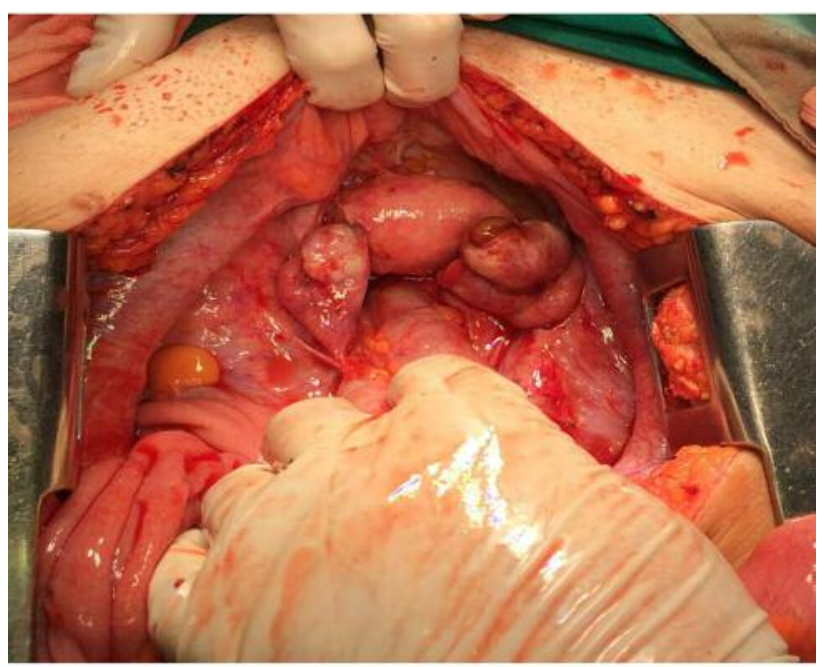

Figure 3. Bilateral ovarian cysts involving the rectosigmoidian loop.

ileum resection being performed in all seven cases. In two cases the authors reported association of rectosigmoidian resection and ileum resection. The first case was the one of a 30-year-old patient who had been previously submitted to 
medical treatment with oral contraceptives, followed by rectosigmoidian resection, ileal resection, partial colpectomy and uterosacral ligament resection. The second one was a 41year-old patient previously submitted to levonorgestrel treatment followed by hysterectomy with bilateral adnexectomy, ileum resection, partial colpectomy, double adnexectomy and rectosigmoidectomy (21).

\section{Conclusion}

Although it is a common situation, bowel involvement in patients with endometriosis usually occurs at the level of the rectosigmoidian loop, the theory of retrograde menstruation in association with the close proximity of the left tubal orifice and the rectosigmoidian loop probably being the right explication. However, association with small bowel involvement causing small bowel obstruction is a rare situation, only few cases being described so far. However, this scenario should not be omitted whenever the patient is known as having a past history of endometriosis.

\section{References}

1 Weed JC and Ray JE: Endometriosis of the bowel. Obstet Gynecol 69: 727-730, 1987.

2 Chapron C, Chopin N, Borghese B, Foulot H, Dousset B, Vacher-Lavenu MC, Vieira M, Hasan W and Bricou A: Deeply infiltrating endometriosis: pathogenetic implications of the anatomical distribution. Hum Reprod 21: 1839-1845, 2006.

3 Slesser AA, Sultan S, Kubba F and Sellu DP: Acute small bowel obstruction secondary to intestinal endometriosis, an elusive condition: a case report. World J Emerg Surg 5: 27, 2010.

4 Siristatidis CS: What have the 'omics done for endometriosis? Med Sci Monit 15: RA116-RA123, 2009.

5 Attar A and Lagorce C: Small bowel obstruction caused by endometriosis. Clin Gastroenterol Hepatol 5: A30, 2007.

6 MACAFEE $\mathrm{CH}$ and GREER HL: Intestinal endometriosis. A report of 29 cases and a survey of the literature. J Obstet Gynaecol Br Emp 67: 539-555, 1960.

7 Ridha JR and Cassaro S: Acute small bowel obstruction secondary to ileal endometriosis: report of a case. Surg Today 33: 944-947, 2003.

8 Bassi MA, Podgaec S, Dias Junior JA, Sobrado CW and Filho DA: (Bowel endometriosis: a benign disease?). Rev Assoc Med Bras (1992) 55: 611-616, 2009.

9 Garg NK, Bagul NB, Doughan S and Rowe PH: Intestinal endometriosis - a rare cause of colonic perforation. World $\mathrm{J}$ Gastroenterol 15: 612-614, 2009.
10 Sampson JA: Benign and malignant endometrial implants in the peritoneal cavity, and their relation to certain ovarian tumors. Surg Gynecol Obstet 38: 287-311, 1924.

11 Minh HN, Smadja A and Orcel L: (An integrated histogenetic concept of internal and external endometriosis). J Gynecol Obstet Biol Reprod (Paris) 15: 29-35, 1986.

12 Donnez J, Spada F, Squifflet J and Nisolle M: Bladder endometriosis must be considered as bladder adenomyosis. Fertil Steril 74: 1175-1181, 2000.

13 Anaf V, El N, I, Simon P, Van de SJ, Fayt I, Simonart T and Noel JC: Preferential infiltration of large bowel endometriosis along the nerves of the colon. Hum Reprod 19: 996-1002, 2004.

14 Teke Z, Aytekin FO, Atalay AO and Demirkan NC: Crohn's disease complicated by multiple stenoses and internal fistulas clinically mimicking small bowel endometriosis. World $\mathrm{J}$ Gastroenterol 14: 146-151, 2008.

15 Taylor RN, Yu J, Torres PB, Schickedanz AC, Park JK, Mueller MD and Sidell N: Mechanistic and therapeutic implications of angiogenesis in endometriosis. Reprod Sci 16: 140-146, 2009.

16 Kavallaris A, Kohler C, Kuhne-Heid R and Schneider A: Histopathological extent of rectal invasion by rectovaginal endometriosis. Hum Reprod 18: 1323-1327, 2003.

17 Beltran MA, Tapia QT, Araos HF, Martinez GH and Cruces KS: (Ileal endometriosis as a cause of intestinal obstruction. Report of two cases). Rev Med Chil 134: 485-490, 2006.

18 Vercellini P, Chapron C, Fedele L, Gattei U, Daguati R and Crosignani PG: Evidence for asymmetric distribution of lower intestinal tract endometriosis. BJOG 111: 1213-1217, 2004.

19 Markham SM, Carpenter SE and Rock JA: Extrapelvic endometriosis. Obstet Gynecol Clin North Am 16: 193-219, 1989.

20 Sali PA, Yadav KS, Desai GS, Bhole BP, George A, Parikh SS and Mehta HS: Small bowel obstruction due to an endometriotic ileal stricture with associated appendiceal endometriosis: A case report and systematic review of the literature. Int J Surg Case Rep 23: 163-168, 2016.

21 Lopez Carrasco A, Hernandez Gutierrez A, Hidalgo Gutierrez P, Gonzalez RR, Marijuan Martín JL, Zapardiel I and Santiago García J: Ileocecal endometriosis: diagnosis and management. Taiwan J Obstet Gynecol 56: 243-246, 2017. 